\section{New horizons}

Cosmology Now. Edited by Laurie John. Pp. 168. 8 plates. (BBC: London, November 1973.) $£ 2.75$.

THIs is, without doubt, the best introduction to modern cosmology available in book form. The list of contributors, each of whom provides one or two chapters, reads like a role of honour of the young cosmologists who have been at the forefront of the revolution in the subject over the past twenty years, with the addition of a couple of 'grand old men' such as Professor W. H. McCrea (whose outlook is certainly as youthful as that of any of the other contributors). For once, a claim made in the cover blurb (quoting Sir Bernard Lovell's introduction) can be taken at face value: this really is "the best description of the universe which can be given today".

But lest it seem that $I$ am in the pay of the book's editor I should, perhaps, elaborate on the areas where it falls short of perfection, in the hope that some of these shortcomings might be rectified in a later edition. There is one glaring omission-in a book which is sure to attract the casual reader, and to whet his appetite for more cosmological fare, there is no bibliography or guide to further reading. Compared to this, the other points to which I take exception are only minor irritations, largely due, it would seem, to the editor's unfamiliarity with astronomy. Laurie John produced the radio series from which the book derives, and no doubt it is fitting that he should provide the introductory paragraphs which head each chapter. But surely among the wealth of cosmological talent contributing to the book someone could have checked these paragraphs, and the captions to the illustrations, for astronomical howlers?

Reference to quasars as "star like objects that may lie near the edge of the universe" is certainly misleading without qualification; far worse is the caption to Plate 8: "The star arrowed is a quasar"! It also seems a shame to introduce Martin Rees solely as "Plumian Professor of Astronomy" when the rest of his title ("and Experimental Philosophy") relates so appositely to the content of the book in general and his own contribution in particular. Apart from the quote from Sir Bernard Lovell the cover blurb is irritatingly out of key with the book, dragging in a reference to "the "black hole', that ever-growing celestial maelstrom" which is likely to cause further distress to those astronomers already infuriated by the extravagant popularisations of black hole astronomy which have appeared recently; they can, however, safely ignore the words on the cover and be guided as to the true nature of the book by Professor Roger Penrose, who points out that no astronaut is likely to encounter a black hole by accident-" "they would have to seek out a black hole deliberately if they wished to experience this "ultimate trip" ". My final objection is purely a personal one-I have no liking for Professor John Taylor's homespun cosmological philosophy. But that may indicate a failing in me rather than in him.

Such a small catalogue of complaints shows, perhaps, how good the book is in general. As far as the detailed exposition of cosmological ideas is concerned there is little to say here except that all the contributions are readable and intelligible without any prior mathematical knowledge, and the few illustrations are equally clear and provide a valuable addition to the text. Quite apart from the 'introductory text' aspect of this volume, however, the contributions provide a valuable insight into the personalities of the contributors and the kind of bric-a-brac of odd bits of information which make it valuable in historical terms. I was particularly intrigued, for example, to discover from Dennis Sciama's contribution that Dicke and his colleagues were unaware of Gamow's earlier 'hot big bang' model of the Universe when they reintroduced the idea in 1965; I would have thought every astronomer remembered Gamow's work, if only because of his cunning choice of co-authors in writing the classic paper by Alpher, Bethe and Gamow-certainly $\mathbf{I}$ knew of this work in 1965 , when much to my delight I discovered that paper as part of an undergraduate project. And certainly once discovered it is never forgotten.

Professor J. V. Narlikar also produces a memorable sentence: "Until the observational situation clarifies further it is premature to write off the steady state theory". That is particularly encouraging for those, like myself, who have a fondness for the steady state theory, and it does seem that the model has regained some ground since the dark days of the mid-1960s. But I must confess that while my gut reaction is still 'steady state, right or wrong' my head tells me that the evidence in favour of the hot big bang is very nearly overwhelming.

I also have a fondness for Mach's Principle, first propounded by Bishop Berkeley and today, it seems, rather more widely approved than steady state cosmologies. And when investigating the triumph of head over gut in the big bang-steady state dilemma, the future historian of science will no doubt be intrigued to learn from Sciama's contribution that he was persuaded, in 1966 , of the great difficulties presented by trying to explain radio observations in steady state theory terms by "my student, Martin Rees". That same Martin Rees contributes to the book in his capacity now as Plumian Professor; an indication of just how much ground has been covered by essentially one generation of cosmologists.

So the book is well suited to the casual reader, to the historian of science, to specialist astronomers and to students. With an eye particularly to the needs of the latter, I hope that it may soon be available in paperback form at an even lower price, although it is certainly good value already.

JOHN GRIBBIN

\section{Descriptive embryology}

Embryology and Phylogeny in Annelids and Arthropods. By D. T. Anderson. Pp. xiv +495 . (Pergamon: Oxford and New York, October 1973.) $£ 8$.

THE human brain, it would seem, is well adapted to the recognition and analysis of two-dimensional patterns, corresponding to retinal images, but is, as all teachers of anatomy know, far less adept at dealing with three-dimensional configurations. In embryonic development we are confronted with threedimensional patterns changing in time; to produce a total image of such a development as a whole would be equivalent to thinking in four dimensions. To go even beyond this, in seeking to analyse a comparison between the embryonic developments of a whole series of animal species would in effect add even more dimensions to the problem. The daunting difficulty of this goes far to explain the recent unpopularity of studies in comparative descrip- 